\title{
Causes and management of post-partum hemorrhage at tertiary care center, Rajasthan, India
}

\author{
Kamlesh Gora, Anju Depan, Kanti Yadav, Devendra Benwal*
}

Department of Obstetrics and Gynecology, JLN Medical College, Ajmer, Rajasthan, India

Received: 06 April 2019

Accepted: 08 May 2019

\section{*Correspondence:}

Dr. Devendra Benwal,

E-mail: dr.kamleshgora30@gmail.com

Copyright: (C) the author(s), publisher and licensee Medip Academy. This is an open-access article distributed under the terms of the Creative Commons Attribution Non-Commercial License, which permits unrestricted non-commercial use, distribution, and reproduction in any medium, provided the original work is properly cited.

\begin{abstract}
Background: $\mathrm{PPH}$ is responsible for $25 \%$ of all maternal deaths. In India, PPH incidence in India is $2 \%-4 \%$ following vaginal delivery and 6\% following cesarean section. PPH as the important cause of $19.9 \%$ of maternal mortality in India. The objectives of the study were to study the incidence, risk factors, cause, morbidity and mortality pattern and management of PPH.

Methods: This is a cross-sectional study conducted among 102 pregnant women selected by convenient sampling and admitted in labour room during the study period who will be deliver by vaginally or by caesarean section. The patient having PPH were divided into two groups: Group I: Patients having primary atonic PPH, Group II: Patients having traumatic PPH.

Results: Mean age of participants was 33.6 and 32.9 years, 59.3 and 51.2 have '0' parity, mean BMI 22.8 and 23.9 $\mathrm{kg} / \mathrm{m} 2,34.6 \%$ and 17.1 babies were delivered by LSCS, $11.7 \%$ and $12.2 \%$ have history of PPH in the group of atonic and traumatic respectively. In the group of atonic PPH cases, $77.2 \%, 15.4 \%, 4.3 \%$ and $3.1 \%$ cases managed by the method of 'Uterotonics $+<2$ blood transfusions', 'Uterotonics $+>2$ blood transfusions', 'Perineal Tear Repair' and 'Surgical Intervention' respectively. All the traumatic PPH cases $(100.0 \%)$ were managed by 'surgical intervention'.

Conclusions: A multi-disciplinary approach include medical, mechanical, surgical and radiological is required in severe haemorrhage. Availability of blood and blood products is very crucial. Prediction and assessment of blood loss and timely identification of uterine atony are remaining the cornerstone for prompt and effective management of PPH.
\end{abstract}

Keywords: Atonic PPH, Post-partum Hemorrhage, Traumatic PPH, Uterine Atony

\section{INTRODUCTION}

PPH can be defined as fall in hematocrit $>10 \% .{ }^{1}$ Primary $\mathrm{PPH}$ is defined as, bleeding occurring within 24 hours of birth and secondary PPH defined as bleeding in excess of normal lochia after 24 hours and up to six weeks postpartum. $^{2-4}$

As per the data of World Health Organization (WHO), $\mathrm{PPH}$ is the most common cause of maternal mortality and morbidity worldwide and is responsible for $25 \%$ of all maternal deaths. ${ }^{5,6}$ According to WHO, PPH complicate the $10.5 \%$ of live births and around $13,795,000$ women suffered PPH with 13,200 maternal deaths in the year $2000 .^{7}$ In India, PPH incidence in India is $2 \%-4 \%$ following vaginal delivery and $6 \%$ following cesarean section. PPH as the important cause of $19.9 \%$ of maternal mortality in India. ${ }^{8}$ About 75 to $90 \%$ of $\mathrm{PPH}$ cases are caused by uterine atony. ${ }^{9}$ Almost $60-70 \%$ of atonic PPH incidence can be prevented by Active management of third stage of labour. Monitoring of pulse, blood pressure, bleeding during fourth stage of labour and using bedside tool, Modifid Early Obstetric Warning System (MEOWS) in all obstetric inpatient are important and crucial to prevent morbidity and mortality. So, the present study was conducted with the objective to study the 
incidence, risk factors, cause, morbidity and mortality pattern and management of $\mathrm{PPH} .^{10,11}$

\section{METHODS}

This is a cross-sectional study conducted among 102 pregnant women selected by convenient sampling and admitted in labour room during the study period who will be deliver by vaginally or by caesarean section done at Department of Obstetrics and Gynaecology, J.L.N. Medical College, Ajmer, Rajasthan, India during January 2018 to December 2018 after ethical permission from Institutional Ethical Committee. Study included all the patients of Singleton term pregnancy with cephalic and normal placenta, Patients who develop primary atonic PPH defined as uterine atony after delivery of placenta $(<24 \mathrm{hr})$ that leads to blood loss, Patients who developed traumatic PPH defined as any trauma to the genital tract, Low risk LSCS cases. Study excluded all referred cases of PPH who delivered outside study setting, All cases of secondary PPH, All cases of severe anaemia ( $\mathrm{Hb}$ $<7 \mathrm{gm} \%$ ), hypertension, jaundice, heart disease, epilepsy, bronchial asthma, renal disease, and known hypersensitivity to prostaglandins, all the cases of bleeding disorders, multiple pregnancy, polyamnios, intrauterine deaths, multigravida, twins pregnancy etc, All cases of placenta pravia, previous 2 LSCS, instrumental delivery, All LSCS case who is high risk LSCS cases. The patient having PPH were divided into two groups: Group I: Patients having primary atonic PPH (162 cases), Group II: Patients having traumatic PPH (41 cases).

\section{Group I}

After delivery of placenta, uterus was palpated per abdominally and if the uterus was atonic and the blood loss was more than normal, bimanual uterine massage was done and first line medical intervention begin immediately. Volume replacement by crystalloids and blood transfusion has been done in each case as per requirement. As per protocol standard policy was adopted for these supportive measures.

\section{Group II}

Those patients who have any trauma to the genital tract with vaginal bleeding despite a well contracted uterus were considered to have traumatic $\mathrm{PPH}$.

Collected data was entered in the excel data sheet and data analysis was done with the help of Epi. Info.7.2 software.

\section{RESULTS}

Table 1 shows that maximum number of patients among 203 selected patients belonged in 30- 40 years age group i.e. $67.3 \%$ in Atonic PPH and $68.3 \%$ in Traumatic PPH ( $>0.05)$. Highest number of participants $59.3 \%$ and
$51.2 \%$ have ' 0 ' parity followed by $26.5 \%$ and $29.3 \%$ have parity ' 1 ' in the group of atonic and traumatic respectively $(\mathrm{p}>0.05)$. Almost $54.9 \%$ and $68.3 \%$ participants were resided in rural area in the group of atonic and traumatic respectively $(\mathrm{p}>0.05)$. Highest number of participants $63.6 \%$ and $58.5 \%$ were belonged to the group of BMI group of 18.5 to 24.9 atonic and traumatic respectively $(\mathrm{p}>0.05)$. Vaginal delivery was noted in $65.4 \%$ and $82.9 \%$ in the group of atonic and traumatic respectively $(\mathrm{p}<0.05)$. History of severe $\mathrm{PPH}$ was observed in $11.7 \%$ and $12.2 \%$ in the group of atonic and traumatic respectively $(\mathrm{p}>0.05)$. More than $3.5 \mathrm{~kg}$ ' observed in $93.2 \%$ and $92.7 \%$ in the group of atonic and traumatic respectively ( $\mathrm{p}>0.05)$.

Table 1: Socio-clinical parameters of study participants $(\mathrm{N}=203)$.

\begin{tabular}{|c|c|c|c|}
\hline Parameters & $\begin{array}{l}\text { Atonic } \\
(\mathrm{n}=162)\end{array}$ & $\begin{array}{l}\text { Traumatic } \\
(n=41)\end{array}$ & $\begin{array}{l}\text { P } \\
\text { value* }\end{array}$ \\
\hline \multicolumn{3}{|l|}{ Age } & \multirow{5}{*}{$>0.05$} \\
\hline $20-30$ & $49(30.2)$ & $11(26.8)$ & \\
\hline $30-40$ & $109(67.3)$ & $28(68.3)$ & \\
\hline$>40$ & $4(2.5)$ & $2(4.9)$ & \\
\hline Mean \pm SD & $33.6 \pm 7.4$ & $32.9 \pm 5.8$ & \\
\hline \multicolumn{3}{|l|}{ Parity } & \multirow{5}{*}{$>0.05$} \\
\hline 0 & $96(59.3)$ & $21(51.2)$ & \\
\hline 1 & $43(26.5)$ & $12(29.3)$ & \\
\hline 2 & $16(9.9)$ & $5(12.2)$ & \\
\hline$\geq 3$ & $7(4.3)$ & $3(7.3)$ & \\
\hline \multicolumn{3}{|l|}{ Residence } & \multirow{3}{*}{$>0.05$} \\
\hline Rural & $89(54.9)$ & $28(68.3)$ & \\
\hline Urban & $73(45.1)$ & $13(31.7)$ & \\
\hline \multicolumn{3}{|l|}{ BMI (kg/m2) } & \multirow{6}{*}{$>0.05$} \\
\hline$<18.5$ & $9(5.6)$ & $1(2.4)$ & \\
\hline $18.5-24.9$ & $103(63.6)$ & $24(58.5)$ & \\
\hline $25-29.9$ & $30(18.5)$ & $10(24.4)$ & \\
\hline$\geq 30$ & $20(12.3)$ & $6(14.6)$ & \\
\hline Mean \pm SD & $22.8 \pm 3.4$ & $23.9 \pm 3.8$ & \\
\hline \multicolumn{3}{|c|}{ Mode of Delivery } & \multirow{3}{*}{$<0.05$} \\
\hline Vaginal & $106(65.4)$ & $34(82.9)$ & \\
\hline LSCS & $56(34.6)$ & $7(17.1)$ & \\
\hline \multicolumn{3}{|c|}{ History of severe PPH } & \multirow{3}{*}{$>0.05$} \\
\hline Present & $19(11.7)$ & $5(12.2)$ & \\
\hline Absent & $143(88.3)$ & $36(87.8)$ & \\
\hline \multicolumn{3}{|c|}{ Hb level (in g/dL) } & \multirow{3}{*}{$>0.05$} \\
\hline$\leq 9.0$ & $16(9.9)$ & $4(9.8)$ & \\
\hline$\geq 9.1$ & $146(90.1)$ & $37(90.2)$ & \\
\hline \multicolumn{3}{|c|}{ Birth Weight (in kg) } & \multirow{3}{*}{$>0.05$} \\
\hline $\begin{array}{l}\text { Normal ( } 2.5 \text { to } \\
3.5)\end{array}$ & $11(6.8)$ & $3(7.3)$ & \\
\hline Higher $(>3.5)$ & $151(93.2)$ & $38(92.7)$ & \\
\hline
\end{tabular}

Table 2 shows that all the traumatic PPH cases (100.0\%) were managed by 'surgical intervention'. In the group of atonic PPH cases, $77.2 \%, 15.4 \%, 4.3 \%$ and $3.1 \%$ cases 
managed by the method of 'Uterotonics $+<2$ blood transfusions', 'Uterotonics + >2blood transfusions', 'Perineal Tear Repair' and 'Surgical Intervention' respectively $(\mathrm{p}<0.05)$.

Table 2: Management of PPH (N=203).

\begin{tabular}{|c|c|c|c|}
\hline $\begin{array}{l}\text { Type of } \\
\text { Intervention }\end{array}$ & $\begin{array}{l}\text { Atonic } \\
(\mathrm{n}=162)\end{array}$ & $\begin{array}{l}\text { Traumatic } \\
(\mathrm{n}=41)\end{array}$ & $\begin{array}{l}\text { P } \\
\text { value* }\end{array}$ \\
\hline $\begin{array}{l}\text { Uterotonics } \\
+<2 \text { blood } \\
\text { transfusions }\end{array}$ & $\begin{array}{l}125 \\
(77.2)\end{array}$ & $00(0.0)$ & \multirow{4}{*}{$<0.05$} \\
\hline $\begin{array}{l}\text { Uterotonics }+ \\
>\text { 2blood transfusions }\end{array}$ & $\begin{array}{l}25 \\
(15.4)\end{array}$ & $00(0.0)$ & \\
\hline Perineal Tear Repair & $7(4.3)$ & $00(0.0)$ & \\
\hline Surgical Intervention & $5(3.1)$ & $41(100.0)$ & \\
\hline
\end{tabular}

Figure 1 shows that $40.0 \%, 40.0 \%$ and $1.0 \%$ cases were surgically managed by the methods B Lynch, Manual removal of placenta and Obstetric Hysterectomy respectively. Almost $78.0 \%, 12.2 \%$ and $9.8 \%$ cases were surgically managed by the methods Cervical exploration with repair, Manual removal of placenta and Uterine packing or balloon catheter(tamponade) $(\mathrm{p}<0.05)$.

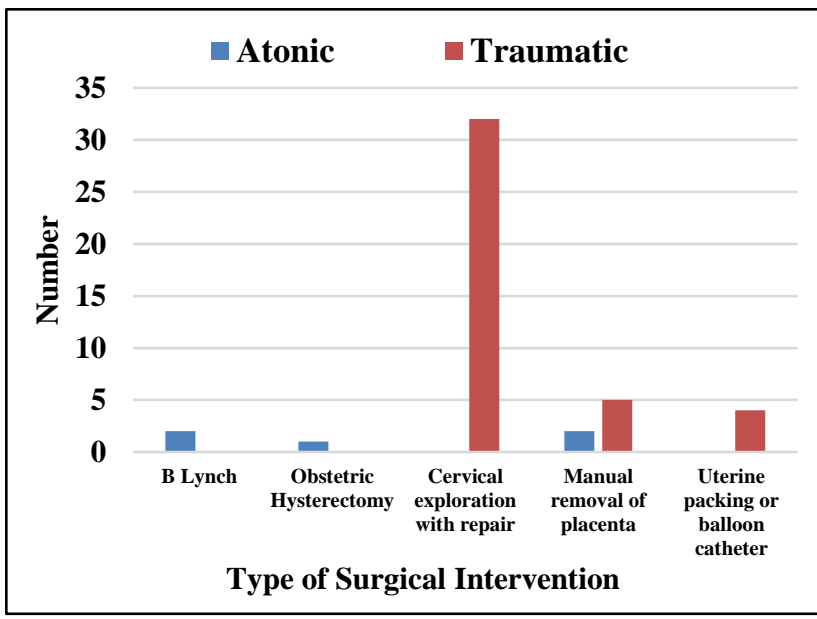

Chi-square Test, $\mathrm{p}$ value $=0.001$, Significant

Figure 1: Surgical intervention in PPH $(\mathrm{N}=46)$.

\section{DISCUSSION}

Study found $79.8 \%$ cases of atonic PPH and $20.2 \%$ cases of traumatic PPH. These findings are correlate with the study done by Tasneem F et al, Sheikh L et al, Sheikh L et al. ${ }^{12-14}$ Highest number of participants $67.3 \%$ and $68.3 \%$ were belonged to the age group of ' $30-40$ years' in atonic and traumatic respectively. This finding is comparable with the study done by Mehrabadi A et al, Ngwenya $S$ et al. ${ }^{15,16}$ Highest number of participants $59.3 \%$ and $51.2 \%$ have ' 0 ' parity followed by $26.5 \%$ and $29.3 \%$ have parity ' 1 ' in the group of atonic and traumatic respectively. Present study finding is correlate with the study done by Sadiq GU et al, and Tsu VD et al. ${ }^{17,18}$ Mean BMI was 22.8 $\pm 3.4 \mathrm{~kg} / \mathrm{ht}^{2}$ and $23.9 \pm 3.8$ $\mathrm{kg} / \mathrm{ht}^{2}$ in the group of atonic and traumatic PPH respectively. This finding is comparable with the study done by Paglia MJ et al, and Butwick AJ et al. ${ }^{19,20}$ Vaginal delivery was noted in $65.4 \%$ and $82.9 \%$ in the group of atonic and traumatic respectively and LSCS was noted in $34.6 \%$ and $17.1 \%$ the group of atonic and traumatic respectively. This finding is correlate with the study done by Loverro $\mathrm{G}$ et al, and Holm $\mathrm{C}$ et al. ${ }^{21,22} \mathrm{PPH}$ treatment includes four elements, communication, resuscitation, monitoring investigation and arresting the bleeding which must be taken simultaneously. Main therapeutic goals of management of massive haemorrhage is to maintain haemoglobin $>8 \mathrm{gm} / \mathrm{dl}$, platelet count $>75 \times 109 / 1$, prothrombin $<1.5 \times$ mean control, activated prothrombin time $<1.5 \mathrm{x}$ mean control, fibrinogen $>1.0 \mathrm{gm} / \mathrm{l}^{11,23}$

\section{CONCLUSION}

$\mathrm{PPH}$ is the leading cause of maternal mortality and morbidity in globally. Identification of high-risk factors and active management of labour is very crucial for the prevention of PPH. A multi-disciplinary approach include medical, mechanical, surgical and radiological is required in severe haemorrhage. Availability of blood and blood products is very crucial. Prediction and assessment of blood loss and timely identification of uterine atony are remaining the cornerstone for prompt and effective management of PPH.

\section{Funding: No funding sources}

Conflict of interest: None declared

Ethical approval: The study was approved by the Institutional Ethics Committee

\section{REFERENCES}

1. Wainscot MP. Pregnancy, postpartum hemorrhage; 2004. Available at: http://www.emedicine.com. Accessed 24 December 2018.

2. World Health Organization. Reducing the Global Burden: Postpartum Hemorrhage; 2008:1 -8. Available

at: https://www.who.int/medicines/areas/priority_medici nes/Ch6_16PPH.pdf. Accessed 20 March 2019.

3. Khan KS, Wojdyla D, Say L, Gümezoglu AM, Look PFA. WHO analysis of causes of maternal death: a systematic review. Lancet. 2006;367(9516):1066-74.

4. Magnann EF, Evans S, Chauhan SP, Lanneau G, Fisk AD. The Length of the Third Stage of Labor and the Risk of Postpartum Hemorrhage. Obstet Gynecol. 2005;105(2):290-3.

5. World Health Organization. WHO Recommendations for the Prevention and Treatment of Postpartum Haemorrhage. World Health Organization, Geneva; 2012. Available at: https://www.who.int/reproductivehealth/publications /maternal_perinatal_health/9789241548502/en/. Accessed 20 March 2019. 
6. World Health Organization. Maternal mortality in 2005: estimates developed by WHO, UNICEF, UNFPA and the World Bank, WHO, Geneva, Switzerland; 2007. Available at: https://www.who.int/whosis/mme_2005.pdf.

Accessed 20 March 2019.

7. Cameron MJ, Robson SC. Vital statistics: an overview, in A Textbook of Postpartum Hemorrhage. In: CB-Lynch, et al. (Eds.), A Comprehensive Guide to Evaluation, Management and Surgical intervention, Sapiens Publishing, $1^{\text {st }}$ Ed.; 2006:17-34.

8. Registrar General, India and Centre for Global Health Research, Maternal Mortality in India, 19972003: Trends, Causes and Risk Factors, New Delhi: Registrar General, India; 2006:1-40.

9. Haeri S, Dildy GA. Maternal Mortality From Haemorrhage. Seminars in Perinatology. 2012;36(1):48-55.

10. Mousa HA, Alfievic. Treatment for primary postpartum haemorrage. Cochrane Database Syst Rev. 2007;(1):CD003249.

11. Rani PR, Begum J. Recent Advances in the Management of Major Postpartum Haemorrhage A Review. J Clin Diagnos Resea. 2017 Feb;11(2):QE01-QE05.

12. Tasneem F, Sirsam S, Shanbhag V. Clinical study of post partum haemorrhage from a teaching hospital in Maharashtra, India. Int J Reprod Contracept Obstet Gynecol. 2017;6:2366-9.

13. Sheikh L, Najmi N, Khalid U, Saleem T. Evaluation of compliance and outcomes of a management protocol for massive postpartum hemorrhage at a tertiary care hospital in Pakistan. BMC Pregnancy Childbirth. 2011 Apr 13;11:28.

14. Sheikh L, Zuberi NF, Riaz R, Rizvi JH. Massive primary postpartum haemorrhage: setting up standards of care. J-Pakistan Med Assoc. 2006;56(1):26.

15. Mehrabadi A, Hutcheon J, Lee L, Kramer M, Liston $\mathrm{R}$, Joseph K. Epidemiological investigation of a temporal increase in atonic postpartum haemorrhage: a population-based retrospective cohort study. BJOG. 2013;120:853-62.

16. Ngwenya S. Postpartum hemorrhage: incidence, risk factors, and outcomes in a low-resource setting. Int $\mathbf{J}$ Women's Health. 2016;8:647-50.

17. Sadiq GU, Mairiga AG, Geidam AD, Kwanashie HO. How parity affects postpartum haemorrhage prevention in Maiduguri, Nigeria. IJPI's J Hospital Clin Pharma. 2011;1(6):1-6.

18. Tsu VD. Postpartum haemorrhage in Zimbabwe: a risk factor analysis. $\mathrm{Br} \mathrm{J}$ Obstet Gynaecol. 1993;100:327-33.

19. Paglia MJ, Grotegut CA, Johnson LN, Thames B, James AH: Body mass index and severe postpartum hemorrhage. Gynecol Obstet Invest. 2012;73:70-4.

20. Butwick AJ, Abereo A, Bateman BT, Lee HC. Effect of Maternal Body Mass Index on Postpartum Hemorrhage. Anesthesiol. 2018;128:774-8.

21. Loverro G, Greco P, Vimercati A, Nicolardi V, Varcaccio-Garofalo G, Selvaggi L. Maternal complications associated with cesarean section. J Perinat Med. 2001;29:322-6.

22. Holm C, Langhoff-Roos J, Petersen KB, Norgaard A, Diness BR. Severe postpartum haemorrhage and mode of delivery: a retrospective cohort study. BJOG. 2012;119:596-604.

23. Stainsby D, MacLennan S, Thomas D, Isaac J, Hamilton PJ. Guidelines on the management of massive blood loss. Br J Haematol. 2006;135:63441 .

Cite this article as: Gora K, Depan A, Yadav K, Benwal D. Causes and management of post-partum hemorrhage at tertiary care center, Rajasthan, India. Int J Reprod Contracept Obstet Gynecol 2019;8:2425-8. 